\title{
Using Simulated Flue Gas to Rapidly Grow Nutritious Microalgae with Enhanced Settleability
}

\author{
Hannah R. Molitor* and Jerald L. Schnoor
}

Cite This: ACS Omega 2020, 5, 27269-27277

Read Online

ABSTRACT: Favorable microalgal nutrition from waste resources and improved harvesting methods would offset costs for a process that could be scaled up to treat pollution and produce valuable animal feed in lieu of soy protein. Co-benefits include avoidance of carbon dioxide emissions, which may provide an additional revenue stream when carbon markets begin to flourish. To sustainably achieve these goals at scale, barriers to microalgal production such as tolerance for waste streams and dramatic improvement in dewatering and settleability of the microalgae must be overcome. Presently, it is largely assumed that nutritious microalgae, including Scenedesmus obliquus, would be inhibited by $\mathrm{SO}_{x}$ and $\mathrm{NO}_{x}$ in flue gases and settle slowly as discrete

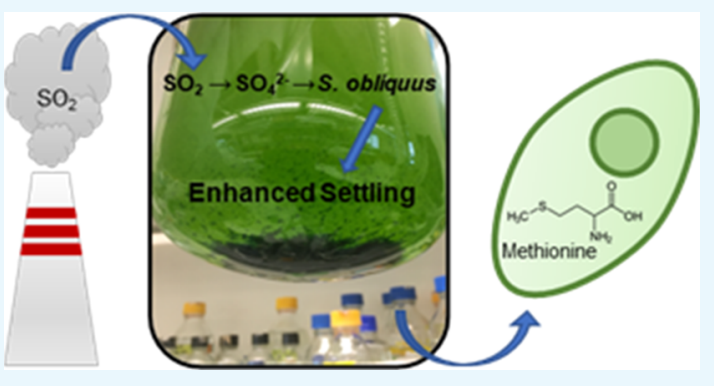
particles. Studies conducted with a $2 \mathrm{~L}$ photobioreactor, sparged with simulated coal-fired power plant flue gas, demonstrated that both biomass productivity and settling rates were increased. The average maximum biomass productivity was $700 \pm 40 \mathrm{mg} \mathrm{L}^{-1} \mathrm{~d}^{-1}$, which significantly exceeded that of the control culture $(510 \pm 40 \mathrm{mg} \mathrm{L}-1$ $\left.\mathrm{d}^{-1}\right)$. Thirty-minute trials of modeled bulk settling showed rapid coagulation, likely facilitated by extracellular polymeric substances, and compaction when the cultures were grown with simulated emissions. Control cultures, not exposed to the additional toxicants in flue gas, settled as discrete particles and did not show any settling progress within $30 \mathrm{~min}$. Of the $\mathrm{SO}_{2}$ sparged into the cultivation system, $(111 \pm 4) \%$ was captured as either $\mathrm{SO}_{4}{ }^{2-}$ in the medium or fixed in the S. obliquus biomass. The stress of simulatedemissions exposure decreased the S. obliquus protein contents and altered the amino acid profiles but did not decrease the fraction of methionine, a valuable amino acid in animal feed.

\section{INTRODUCTION}

Today, nearly one billion of earth's 7.6 billion people already lack sufficient nutritious food on a regular basis, and this population is predicted to increase by $2-3$ billion by the year 2050. ${ }^{1}$ Crop and livestock production will need to increase in quantity and efficiency using finite agricultural area and water resources to meet global demand. ${ }^{2}$ Microalgae are a promising supplement to conventional agriculture as rapidly and sustainably produced protein-rich biomass. ${ }^{3}$

Direct reuse of waste resources to grow microalgal biomass has the potential to be more efficient than conventional agriculture and avoid direct competition for food between humans and livestock. ${ }^{4}$ However, for microalgae to compete as a cost-effective high-protein supplement, biomass productivity rates must increase, nutritional properties must be maintained by growth on waste resources, and harvesting efficiency must dramatically improve. ${ }^{5}$

Flue Gas as a Source of Carbon for Microalgae. Flue gas waste streams containing $\mathrm{CO}_{2}$ can be diverted to cultivate microalgae, especially if the species is able to tolerate $\mathrm{NO}_{x}$ and $\mathrm{SO}_{x}{ }^{6}$ Tolerance is often strain-dependent and in some cases may be limited to only tolerance for $\mathrm{SO}_{x}{ }^{7}$ Kumar et al. treated coal-powered boiler flue gas, containing $6 \% \mathrm{CO}_{2}$, through mixotrophic cultivation of lipid-rich Chlorella vulgaris for biofuel and removed 64, 62, and $63 \%$ of $\mathrm{CO}_{2}, \mathrm{SO}_{x}$, and $\mathrm{NO}_{x}$, respectively. ${ }^{8}$ Van Den Hende et al. achieved removal efficiencies of $48 \pm 7 \% \mathrm{CO}_{2}, 99 \pm 1 \% \mathrm{SO}_{2}$, and $87 \pm 5 \%$ $\mathrm{NO}_{x}$ from coal-fired power plant emissions containing $12 \%$ $\mathrm{CO}_{2}$ using a consortium of microalgae and bacteria. ${ }^{9}$ Previous studies examined the tolerance of microalgal species for $\mathrm{NO}_{x}$ and $\mathrm{SO}_{x}$ and achieved modest treatment of flue gas but generally ignored the potential of microalgae as animal feed and the possible stimulatory effect of sulfur on the growth of microalgae as a nutrient and on the enrichment of their amino acid profiles.

Flue Gas as a Source of Sulfur for Microalgae. Unlike animals, microalgae are able to assimilate and metabolize inorganic sulfur as sulfate. ${ }^{10,11}$ Although sulfur occurs in relatively high concentrations in oceans $\left(28 \mathrm{mM} \mathrm{SO}_{4}{ }^{2-}\right)$, microalgae adapted to freshwater can be limited by low sulfur concentrations $\left(200 \mu \mathrm{M} \mathrm{SO}{ }_{4}^{2-}\right){ }^{12}$ Given this range of environments, it is unsurprising that marine microalgae, such

Received: July 21, 2020

Accepted: September 30, 2020

Published: October 12, 2020 
as diatoms and dinoflagellates, have characteristically low $\mathrm{C} / \mathrm{S}$ ratios and freshwater microalgae, including chlorophytes, have high $\mathrm{C} / \mathrm{S}$ ratios despite similar culture media. ${ }^{13}$ Generally, freshwater microalgal species have adapted to increase sulfate transport by an order of magnitude, to compensate for sulfurlimiting conditions. ${ }^{14}$

Although work has been done to quantify sulfur limitation of microalgal growth, little has been done to quantify the effects of high sulfate concentrations. ${ }^{11}$ Modeled sodium sulfate effects on Chlamydomonas moewusii predicted growth inhibition at $25 \mathrm{mM}$, but the inhibitory effects were attributed to the increase in culture ionic strength rather than the sulfate ion concentrations specifically. ${ }^{15}$ An additional cause of growth inhibition by $\mathrm{SO}_{x}$ is the increase in medium acidity, which may be overcome by cultivating acidophilic microalgae or by adding a base, decreasing the flue gas flow rate, or using very high inoculum culture densities. ${ }^{16}$ Although confounding inhibition factors and minimum necessary sulfur concentrations have been identified for certain species, this is the first study to demonstrate biomass productivity increases, nutritional changes, and stoichiometric differences attributed to high sulfate concentrations.

Nutritional Qualities of Microalgae as Cattle Feed. Several species of microalgae have high protein contents, but the value of the protein is determined by the amino acid profile and how it compares to that of commercial feed. The first limiting amino acid in cereal crops, lysine, is supplied in adequate quantities by legumes. ${ }^{17}$ However, legumes such as soy that are high in protein and lysine are deficient in methionine. In fact, methionine is the first limiting amino acid in soy-based animal feed and is often required as a feed supplement in cattle operations. ${ }^{18}$ Certain microalgal species are able to supply greater fractions of the sulfur amino acid, methionine, relative to soy, in addition to providing comparable crude protein. ${ }^{19}$ Plants and algae assimilate and reduce sulfate before it is used to synthesize cysteine and subsequently methionine. ${ }^{20}$ Animals are unable to synthesize methionine from cysteine but can convert methionine to cysteine, thus requiring specific quantities of methionine. ${ }^{17}$ The next limiting amino acids are then histidine or threonine for dairy or beef cattle, respectively. ${ }^{21,22}$

Harvesting as an Economic Obstacle. Although microalgae are advantageous in their nutritional qualities, potential to remediate pollution, and use of solar energy, harvesting remains an overwhelming challenge for scale-up and commercialization. ${ }^{23}$ Microalgae have similar density as water and are cultured in very dilute solutions, which makes separation difficult. ${ }^{24}$ Popular separation techniques that rely upon uneconomical chemical or energy inputs include chemical flocculation, centrifugation, filtration, flotation, and electrophoresis. Although gravity sedimentation avoids high energy usage or compromising the product with flocculants, it is often prohibitively slow. All told, microalgal harvesting is often reported as $20-30 \%$ (and as much as $57 \%$ ) of production costs. ${ }^{9,25}$ Alternatives to popular separation techniques are attractive to producers looking to cultivate microalgae in an economical and sustainable manner.

Easily settleable, self-flocculating microalgae would be beneficial for economical cultivation. Extracellular polymeric substances (EPS) are biopolymers excreted by microalgae for aggregation, adhesion, and protection that change microalgal surface charge, flocculation, and settling. ${ }^{26}$ EPS can protect cells from toxic substances, dewatering, or other sources of stress while forming multicellular aggregates that can be rapidly settleable. The characteristics of EPS depend on the species, culture conditions, physiology, and cell age. Under stress from unfavorable culture conditions, some microalgae will produce EPS as a protectant. ${ }^{27}$ The rate of floc formation can depend on the composition of EPS; among other components, sulfate is strongly associated with floc generation. ${ }^{26}$

Here, we show that higher rates of biomass productivity are achieved by Scenedesmus obliquus grown with simulated flue gas than those shown previously in the literature. Also, the potentially inhibitory compounds $\mathrm{NO}_{x}$ and $\mathrm{SO}_{x}$ did not prove to be inhibitory; on the contrary, they stimulated the growth rate of $S$. obliquus. In fact, the biomass productivity of $S$. obliquus grown with simulated flue gas outpaced that of $S$. obliquus grown with $\mathrm{CO}_{2}$-supplemented air. Under the exposure to simulated power plant emissions, microalgal protein content decreased relative to control cultures and the amino acid profile was somewhat altered. However, methionine contents were maintained. Most advantageously, cultivation with simulated flue gas dramatically increased the culture settleability through coagulation and bulk settling.

\section{RESULTS \& DISCUSSION}

Microalgal Growth and Nutrient Utilization. To investigate the effect of potentially inhibitory components of power plant emissions on microalgal biomass productivity, $S$. obliquus was grown with simulated coal-fired power plant emissions and air (with equal $\mathrm{CO}_{2}$ concentrations in each) for comparison. Microalgae grown with simulated emissions reached the stationary phase on Day 6, rather than Day 9 as in the control, and high biomass productivities were achieved (Figure 1). Trial 3 ended one day early, when the cylinder

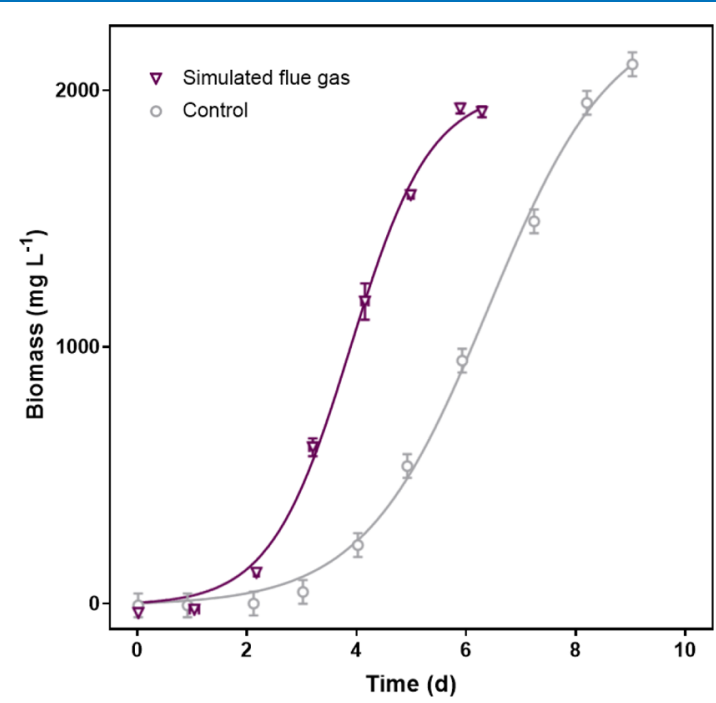

Figure 1. Modeled biomass productivity of $S$. obliquus grown with $12 \% \mathrm{CO}_{2}$ and ultra-zero air (control) and simulated coal-fired power plant emissions. Vertical and horizontal error bars represent standard error $(n=3)$.

supplying $\mathrm{SO}_{2}$ was depleted. The average overall biomass productivity for the three simulated flue gas trials was $323 \pm 2$ $m g \mathrm{~L}^{-1} \mathrm{~d}^{-1}$, whereas the control overall biomass productivity was $223 \pm 13 \mathrm{mg} \mathrm{L}^{-1} \mathrm{~d}^{-1}$.

These values were greater than previous literature rates for $S$. obliquus biomass productivity with simulated emissions. ${ }^{28}$ The 
average maximum biomass productivities of the simulated flue gas and control experiments were $700 \pm 40$ and $510 \pm 40 \mathrm{mg}$ $\mathrm{L}^{-1} \mathrm{~d}^{-1}$, respectively. Thus, equally high rates of maximum biomass productivity were achieved by $S$. obliquus grown with simulated flue gas (at $12 \% \mathrm{CO}_{2}$ ) as the highest literature values (at an optimal $\mathrm{CO}_{2}$ input of $4.1 \%$ ). $^{29}$

From the average maximum biomass productivity and measurements of mass percent carbon, the maximum rate of $\mathrm{CO}_{2}$ utilization was calculated to be $1300 \pm 80 \mathrm{mg} \mathrm{L}^{-1} \mathrm{~d}^{-1}$, which corresponds to $(5.79 \pm 0.01) \% \mathrm{CO}_{2}$ utilization during the exponential growth phase. The calculated overall average rate of $\mathrm{CO}_{2}$ utilization was $600 \pm 4 \mathrm{mg} \mathrm{L}^{-1} \mathrm{~d}^{-1}$. Assuming that carbonate species concentrations in the culture medium $(\mathrm{pH}$ 6.8) were in chemical equilibrium with the sparged $\mathrm{CO}_{2}$, less than $0.1 \% \mathrm{CO}_{2}(0.02 \mathrm{~mol}$ total bicarbonate $)$ went into solution, $(5.79 \pm 0.01) \% \mathrm{CO}_{2}$ was captured by the microalgae, and approximately, 94\% $\mathrm{CO}_{2}$ escaped the reactor. The percent captured by the microalgae could be improved by decreasing the gas flow rate, recycling the off-gas, or using reactors in series.

During each of the three batch trials, sparged $\mathrm{SO}_{2}$ was oxidized in the photobioreactor and accumulated as $\mathrm{SO}_{4}{ }^{2-}$ in the culture medium (Figure 2). Because the original medium

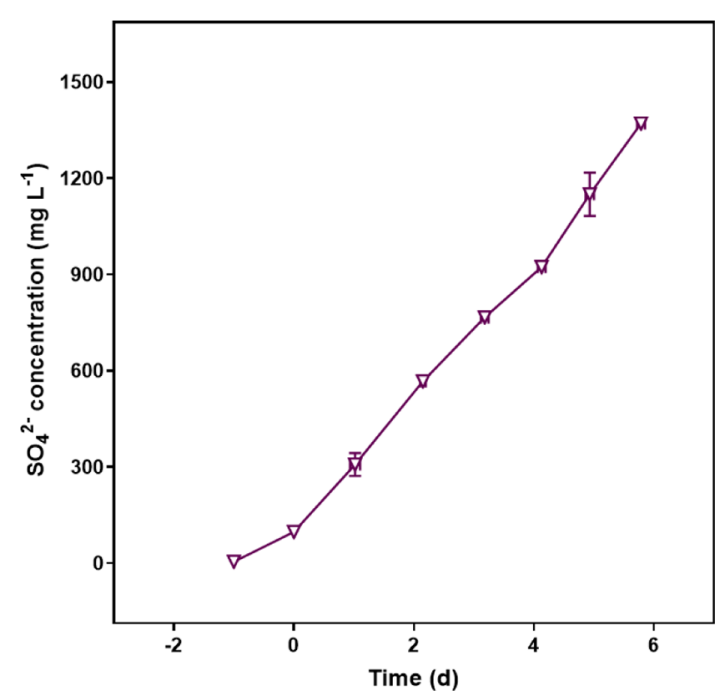

Figure 2. Accumulation of sulfate in the bioreactor inoculated with $S$. obliquus in Bold's Basal medium as it is sparged with simulated coalfired power plant emissions containing sulfur dioxide. Vertical and horizontal error bars represent standard error $(n=3)$. Control did not exceed $34 \mathrm{mg} \mathrm{L}^{-1} \mathrm{SO}_{4}^{2-}$.

was sulfur-free, all accumulated $\mathrm{SO}_{4}{ }^{2-}$ was attributed to the simulated flue gas. Sulfate ions were accumulated in the medium at a rate of $(202 \pm 23) \mathrm{mg} \mathrm{d}^{-1} \mathrm{SO}_{4}{ }^{2-}$. From the total produced biomass and measurements of mass percent sulfur, the average total sulfur capture was estimated to be $(111 \pm$ $4) \%$. Only two percent $[(2.26 \pm 0.07) \%]$ was fixed in the biomass and the remaining mass was measured as sulfate ions in the media. Biomass productivity and growth rates of green microalgae were inhibited in previous studies by high $\mathrm{SO}_{x}$ concentrations, ${ }^{16}$ but in this work, the biomass productivity and growth rates of $S$. obliquus were significantly increased even as sulfate concentrations reached $1300 \mathrm{mg} \mathrm{L}^{-1}$.

Sparged $\mathrm{NO}_{2}$ did not contribute as a significant source of nitrogen to the culture medium; $\mathrm{NO}_{3}{ }^{-}$concentrations were all attributed to the initial $3 \mathrm{~N}-\mathrm{BBM}$, and ion chromatography did not detect any accumulated $\mathrm{NO}_{2}{ }^{-}$. Nitrate was removed at an average rate of $(80 \pm 23) \mathrm{mg} \mathrm{d}^{-1} \mathrm{NO}_{3}{ }^{-}$(Figure 3). Phosphate

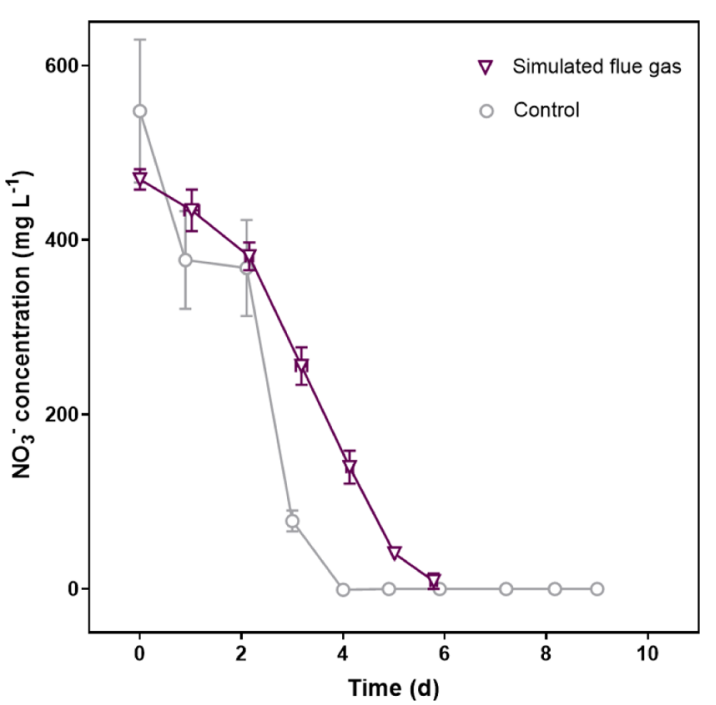

Figure 3. Nitrate removal from inoculated, sparged Bold's Basal medium at $\mathrm{pH}$ 6.8. Vertical and horizontal error bars represent standard deviation $(n=3)$.

was removed at an average rate of $(19 \pm 7) \mathrm{mg} \mathrm{d}^{-1} \mathrm{PO}_{4}{ }^{3-}$ (Figure 4). A lesser quantity of phosphorus was fixed in

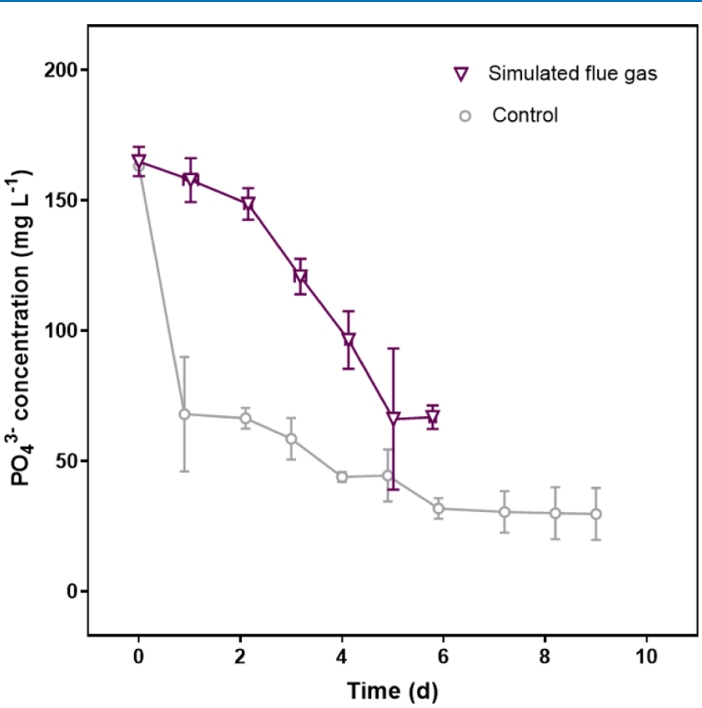

Figure 4. Phosphate removal from inoculated, sparged Bold's Basal medium at $\mathrm{pH}$ 6.8. Vertical and horizontal error bars represent standard deviation $(n=3)$.

microalgae grown with simulated emissions than the control microalgae, $(54 \pm 6) \%$ and $(77 \pm 8) \%$, respectively. At the end of the batch trials, control and simulated emission-sparged media had $(61 \pm 6) \%$ and $(28 \pm 9) \%$ of the initial phosphorus, respectively. The microalgal growth was nitrogen-limited; in each batch, $\mathrm{NO}_{3}{ }^{-}$was exhausted before $\mathrm{PO}_{4}{ }^{3-}$.

Experimental conditions and $\mathrm{CO}_{2} \mathrm{NO}_{3}{ }^{-}$, and $\mathrm{PO}_{4}{ }^{3-}$ concentrations were comparable between control and simulated-emissions experiments, while the oxidation of $\mathrm{SO}_{x}$ to $\mathrm{SO}_{4}{ }^{2-}$ provided dramatically more available sulfur to the microalgal cultures sparged with simulated emissions, which stimulated S. obliquus biomass productivity. 
Table 1. Mass Percent of Carbon, Hydrogen, Nitrogen, Oxygen, Sulfur, and Phosphorus in S. obliquus Grown With Either $\mathrm{CO}_{2}$ and Ultra-Zero Air (Control) or Simulated Flue Gas at pH 6.8

$\begin{array}{lccccccccc} & \text { carbon } & \text { hydrogen } & \text { nitrogen } & \text { oxygen } & \text { sulfur } & \text { phosphorus } & \text { H/C } & \text { N/C } & \text { P/C } \\ \text { simulated flue gas } & 50.7 \pm 0.1 & 7.27 \pm 0.02 & 6.44 \pm 0.04 & 30.8 \pm 0.1 & 0.495 \pm 0.005 & 1.0 \pm 0.1 & 0.14: 1 & 0.13: 1 & 0.020: 1 \\ \text { control } & 46.90 \pm 0.01 & 7.03 \pm 0.03 & 8.61 \pm 0.03 & 32.2 \pm 0.3 & 0.361 \pm 0.008 & 1.3 \pm 0.1 & 0.15: 1 & 0.18: 1 & 0.028: 1\end{array}$

Stoichiometric Comparison of Microalgae Grown with Control and Simulated Flue Gases. The mass percentages of carbon, hydrogen, oxygen, nitrogen, phosphorus, and sulfur were quantified in order to compare the stoichiometry of $S$. obliquus biomass, grown either with simulated flue gas or under control conditions, in a $\mathrm{pH}$-stat system. From the mass percentage values (Table 1), the stoichiometric equations for microalgal growth and composition, under the experimental and control conditions, were developed (eqs 1 and 2).

Control

$$
\begin{array}{r}
\mathrm{H}_{2} \mathrm{PO}_{4}^{-}+92 \mathrm{CO}_{2}+0.3 \mathrm{SO}_{4}{ }^{2-}+15 \mathrm{NO}_{3}^{-}+16.6 \mathrm{H}^{+} \\
+73.2 \mathrm{H}_{2} \mathrm{O} \rightarrow \mathrm{C}_{92} \mathrm{H}_{165} \mathrm{O}_{48} \mathrm{~N}_{15} \mathrm{PS}_{0.3}+129.7 \mathrm{O}_{2}
\end{array}
$$

With simulated flue gas

$$
\begin{aligned}
\mathrm{H}_{2} \mathrm{PO}_{4}^{-} & +130 \mathrm{CO}_{2}+0.5 \mathrm{SO}_{4}^{2-}+14 \mathrm{NO}_{3}^{-}+16 \mathrm{H}^{+} \\
& +102.5 \mathrm{H}_{2} \mathrm{O} \\
\rightarrow & \mathrm{C}_{130} \mathrm{H}_{223} \mathrm{O}_{59} \mathrm{~N}_{14} \mathrm{PS}_{0.5}+175.75 \mathrm{O}_{2}
\end{aligned}
$$

Overall, S. obliquus elemental composition was significantly altered by the simulated flue gas (Table 1 ). The $\mathrm{N} / \mathrm{C}$ mass ratios for the control microalgae and the microalgae exposed to simulated flue gas were $0.18: 1$ and $0.13: 1$, respectively. Under the simulated-emissions condition, microalgae had lower N/C ratios, which supports the decreased $\mathrm{N}$-rich protein content. However, the high $\mathrm{N} / \mathrm{C}$ values suggested that the biomass would be slow to compost as fertilizer. The $\mathrm{P} / \mathrm{C}$ mass ratios for the control microalgae and the microalgae exposed to simulated flue gas were 0.028:1 and 0.020:1, respectively, which is corroborated by the differences in $\mathrm{PO}_{4}{ }^{3-}$ uptake. The microalgal cultures grown with simulated emissions are less $\mathrm{N}$ and P-rich than the control cultures. Microalgae grown under stressful conditions are often less $\mathrm{N}$-rich, and fast-growing producers are less-nutritious. ${ }^{30}$ The energy content, indicated by the $\mathrm{H} / \mathrm{C}$ ratio, was comparable between microalgae grown with control gases and simulated emissions, 0.15:1 and 0.14:1, respectively. For the microalgal biomass grown under control and experimental conditions, the average oxidation states of carbon were -0.31 and -0.52 , respectively. These values indicated that the whole biomass had relatively low energy content and if unprocessed would be better suited for animal feed than as fuel/feedstock. If the biomass was to be combusted for energy, the biomass grown under control conditions would produce $1.76 \mathrm{~g} \mathrm{CO}_{2} / \mathrm{g}$ biomass and the biomass grown with simulated emissions would produce $1.92 \mathrm{~g}$ $\mathrm{CO}_{2} / \mathrm{g}$ biomass (per stoichiometric mole of biomass, under the control and experimental conditions, combustion would produce 92 and $130 \mathrm{~mol} \mathrm{CO}_{2}$, respectively).

S. obliquus Protein Nutritional Qualities. Microalgae are a proven viable food source for domesticated livestock. ${ }^{31}$ Ruminants, through their specialized digestive systems, better obtain the nutritional value from algae than other animals. ${ }^{32}$ In soy- and corn-based cattle feed, methionine and lysine, respectively, are the first limiting amino acids and methionine is frequently required as feed supplements. ${ }^{18}$

Certain microalgae have high protein contents when grown under ideal conditions. To ascertain the nutritional value of microalgae grown with simulated flue gas, the protein content of $S$. obliquus grown with simulated flue gas, S. obliquus grown with $\mathrm{CO}_{2}$-supplemented air (control), and whole soybean was compared (Figure 5). Although the S. obliquus control culture

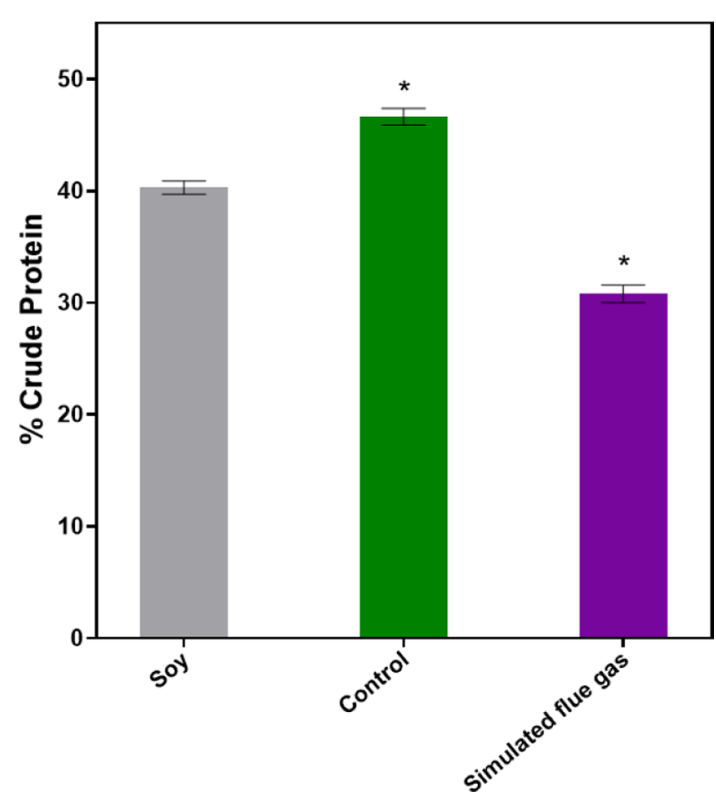

Figure 5. Percent crude protein comparison among whole soybean, $S$. obliquus grown in $3 \mathrm{~N}-\mathrm{BBM}$ and $\mathrm{CO}_{2}$ blended with ultra-zero air, and $S$. obliquus grown in sulfur-free $3 \mathrm{~N}-\mathrm{BBM}$ and simulated coal-fired power plant flue gas. Error bars represent standard deviation $(n=3)$. *Indicates statistical difference from the soy control at $p<0.01, \alpha=$ 0.05 .

protein content exceeded that of soy, that of $S$. obliquus grown with simulated emissions was $30.8 \pm 0.8 \%$, which is lower than that of soy at $40.3 \pm 0.8 \%$. This can be explained by the stress created on the microalgae by the toxic gas mixture, causing the protein synthesis to decrease and the amino acid profile to be altered. The decrease in protein content was consistent with the decrease in mass percent nitrogen under the simulatedemissions condition.

To quantify the changes in microalgal protein quality under the stress of simulated flue gas, the amino acid profiles of $S$. obliquus grown with simulated flue gas, $S$. obliquus grown with $\mathrm{CO}_{2}$-supplemented air (control), and soy were compared (Figure 6). Advantageously, the percent protein that was methionine under both $S$. obliquus culture conditions was equivalent, each more than double that of soy. The lysine content of $S$. obliquus grown with simulated emissions was equal to that of soy and better than that of the control. Overall, the S. obliquus grown with simulated emissions was sufficiently rich in lysine and methionine. The next limiting amino acids, 


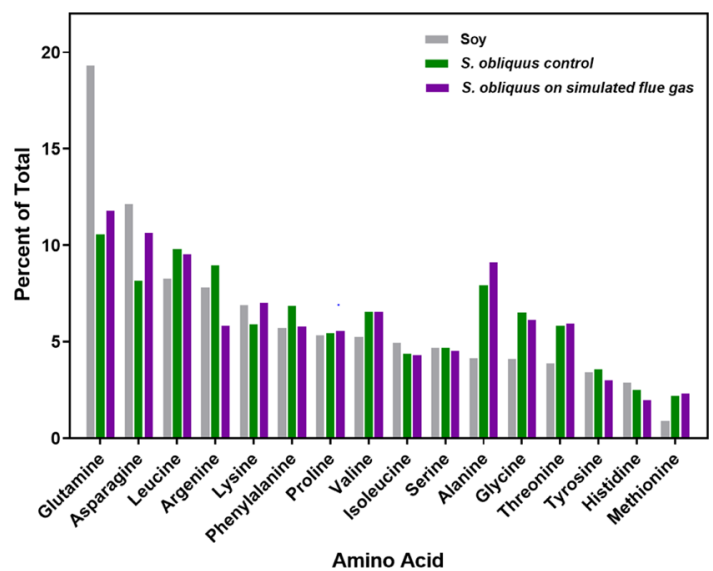

Figure 6. Percent amino acid comparison among whole soybean, $S$. obliquus grown in $3 \mathrm{~N}-\mathrm{BBM}$ and $\mathrm{CO}_{2}$ blended with ultra-zero air, and $S$. obliquus grown in sulfur-free $3 \mathrm{~N}-\mathrm{BBM}$ and simulated coal-fired power plant flue gas. Error was $5 \%$ of the measured values.

after methionine and lysine, are histidine or threonine for dairy or beef cattle, respectively. S. obliquus grown with simulated emissions had poorer histidine content than control S. obliquus and soy. However, both $S$. obliquus grown with simulated emissions and control S. obliquus resulted in $(53 \pm 6)$ and (51 $\pm 8) \%$ greater threonine values than soy, respectively.

Settleability. Harvesting is a serious challenge to the microalgal industry. The size and density of microalgae make discreet cells, or even small clusters, very difficult to filter or settle from the culture medium without additional energy or chemical inputs. Fortunately, the settleability of S. obliquus grown with simulated flue gas emissions was dramatically superior to that grown with the control gases.

During the batch simulated flue gas experiments, microalgal settling was enhanced and it is hypothesized that production of EPS caused foaming, coagulation, and enhanced settling. ${ }^{33}$ Stress-induced production of EPS has previously been shown to cause beneficial coagulation; ${ }^{34}$ in this case, stress is attributed to acidic or toxic flue gas components. ${ }^{35,36}$ EPS facilitated the formation of flocs with good attachment, ${ }^{37}$ but no flocs formed under control conditions (Figure 7). Foaming

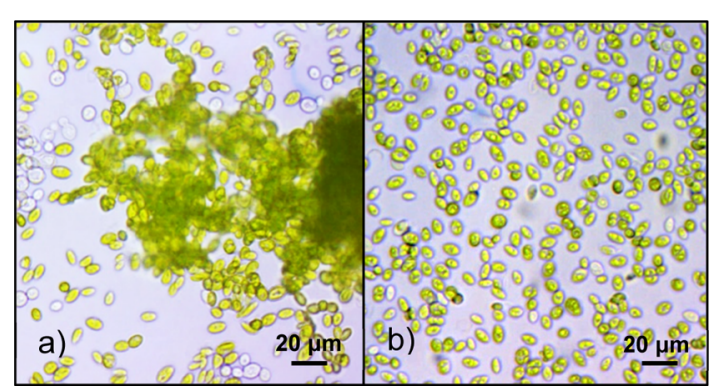

Figure 7. Comparison of (a) S. obliquus grown with simulated flue gas, which coagulated, with (b) S. obliquus grown under control conditions, which did not coagulate.

began on Day 2 and an antifoaming agent was required by Day 3 of each microalgal batch, as foam would otherwise fill the headspace of the photobioreactor and displace significant quantities of biomass from the liquid culture. Foaming did not occur in control cultures. After bacterial contamination and extensive cell death were ruled out as potential causes, it was hypothesized that foaming and coagulation were due to EPS production. $^{26}$

Microalgal biomass settled rapidly if reactor mixing ceased, even temporarily. Experiments conducted to quantify the settling rates (Figure 8) revealed that bulk settling occurred at

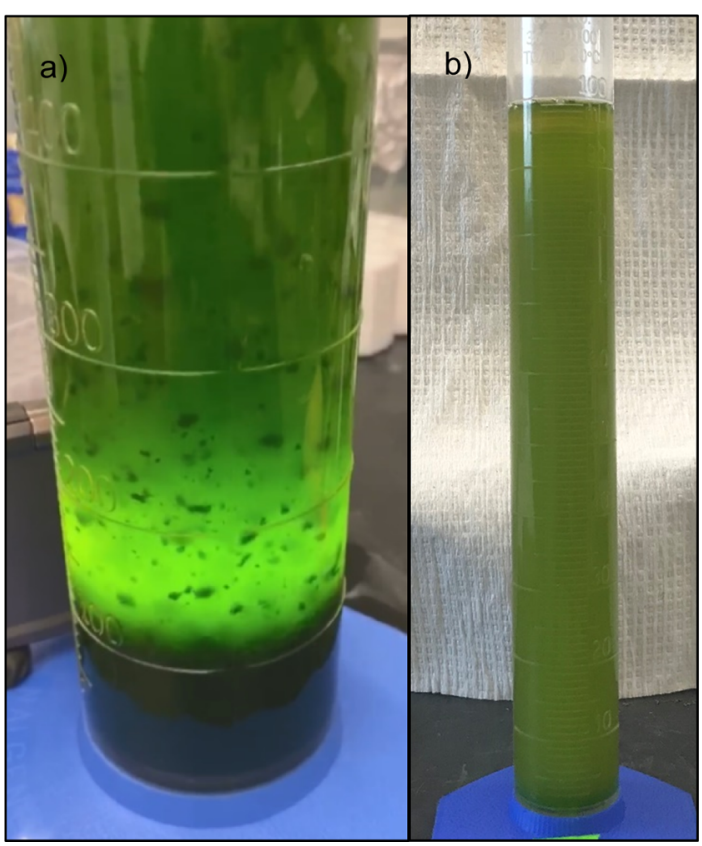

Figure 8. Comparison of (a) S. obliquus grown with simulated flue gas, which settled rapidly in a backlit graduated cylinder, with (b) $S$. obliquus grown under control conditions, which settled slowly.

a nonlinear rate, characterized by first coagulation and then compaction, which was modeled after eq 4 . According to the model, the region of coagulation and rapid settling occurred across the upper $30.2 \pm 0.5 \mathrm{~cm}$, the region of compaction was at $1.8 \pm 0.4 \mathrm{~cm}$, the rate of rapid settling was $1.6 \pm 0.2 \mathrm{~min}^{-1}$, the rate of slowed settling was $0.10 \pm 0.05 \mathrm{~min}^{-1}$, and the minimum compacted bulk height was predicted to be $1.2 \pm 0.2$ $\mathrm{cm}$ (Figure 9).

The average fraction of biomass that settled in bulk, rather than discrete particles, was $58 \pm 17 \%$. The control, S. obliquus grown with $\mathrm{CO}_{2}$-supplemented air, only settles slowly as discrete particles and did not settle significantly within the 30 min trials.

\section{CONCLUSIONS}

The biomass productivity rates of $S$. obliquus grown with simulated power plant flue gas surpassed those of research conducted with $\mathrm{CO}_{2}$-supplemented air at equal $\mathrm{CO}_{2}$ concentrations, despite the additional stresses of nitrogen dioxide, sulfur dioxide, and carbon monoxide. Indeed, the biomass productivity of $S$. obliquus was significantly increased even as $\mathrm{SO}_{4}{ }^{2-}$ concentrations reached $1300 \mathrm{mg} \mathrm{L}^{-1}$. This work exceeds the highest biomass productivity rates, for $S$. obliquus grown with simulated emissions, in the literature.

Experiments with simulated emissions resulted in dramatically improved culture separability, a major obstacle to economical microalgal production. Often, microalgae settle slowly as discrete particles. In this study, coagulated microalgal biomass in each trial was rapidly settled and compacted. 


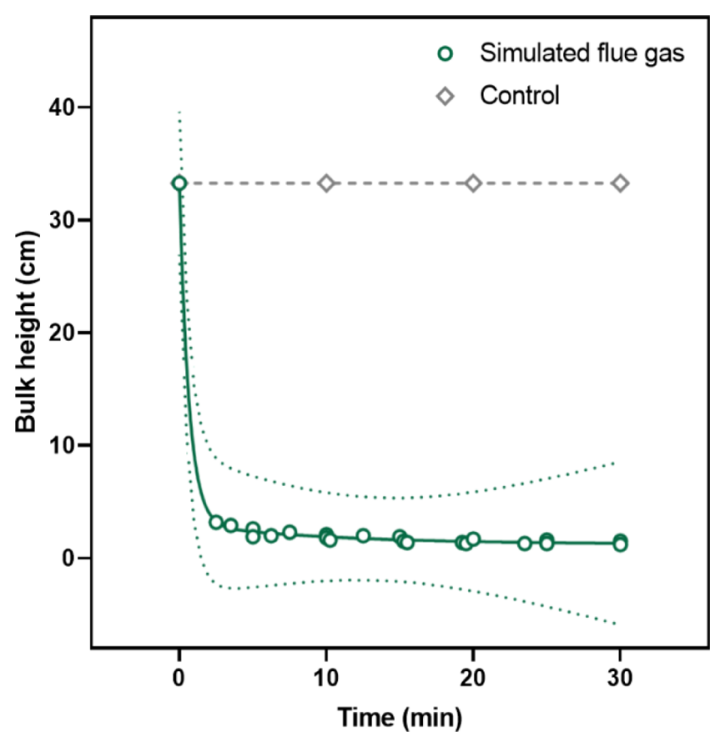

Figure 9. Modeled bulk settling, through coagulation and compaction, of microalgae grown with simulated power plant emissions. The model error is represented with a $95 \%$ confidence interval. Settling of control microalgae was not observed within the 30 min period.

S. obliquus had greater fractions of methionine, the limiting amino acid in cattle feed, relative to soy, although the crude protein value of $S$. obliquus grown with simulated emissions was significantly lower. These results will move forward microalgal $\mathrm{CO}_{2}$ and $\mathrm{SO}_{2}$ capture from industrial and municipal sources and production of sustainable nutritious animal feed.

Our work will help overcome efficiency barriers in producing nutritious salable microalgae and fixing pollutants from flue gas $\left(\mathrm{CO}_{2}, \mathrm{SO}_{x}\right.$, and $\left.\mathrm{NO}_{x}\right)$ in full-scale operations. Thus, use of energy-intensive fertilizer and freshwater resources will decrease, wastewater treatment costs will be offset, and greenhouse gas emissions will be reduced to produce an economical protein source.

\section{MATERIALS AND METHODS}

Experimental Setup. S. obliquus (SAG 276-1) was purchased from the culture collection at Göttingen University in Germany. Species identity was confirmed through DNA extraction, Sanger sequencing with the primers EukA $\left(5^{\prime}\right.$ AACCTGGTTGATCCTGCCAGT- $3^{\prime}$ ) and EukB ( $5^{\prime}$ TGATCCTTCTGCAGG-TTCACCTAC- $\left.3^{\prime}\right),{ }^{38}$ and BLAST sequence search.

A 2 L Sartorius Biostat A bioreactor (Sartorius Stedim Biotech $\mathrm{GmbH}$, Göttingen, Germany), fitted with two red and blue LED panels $\left(280 \mu \mathrm{mol} \mathrm{m}^{-2} \mathrm{~s}^{-1}\right.$; Roleadro, San Francisco, CA, USA), served as a photobioreactor and $\mathrm{pH}$-stat system for microalgal cultivation (see Figure $S 1$ in the Supporting Information). Batch studies of $S$. obliquus were conducted in $1.5 \mathrm{~L}$ of 3-fold nitrogen content, sulfur-free Bold's Basal Medium $^{39}$ (S-free $3 \mathrm{~N}-\mathrm{BBM}$ ) at $27^{\circ} \mathrm{C}, 10 \mathrm{mM}$ HEPES buffer, and $\mathrm{pH} 6.8$ under continuous illumination and a mixing rate of $200 \mathrm{rpm}$. Constant feedback from the bioreactor $\mathrm{pH}$ meter controlled the addition of the base $(1 \mathrm{~N} \mathrm{NaOH})$ to maintain $\mathrm{pH} 6.8$.

A custom Praxair cylinder provided a blend of $1000 \mathrm{ppm}$ $\mathrm{SO}_{2}$ and balance $\mathrm{N}_{2}$, which was mixed 1:1 with the gas from a second custom Praxair cylinder containing $24 \% \mathrm{CO}_{2}, 400 \mathrm{ppm}$
$\mathrm{NO}_{2}, 1000$ ppm CO, $12 \% \mathrm{O}_{2}$, and balance $\mathrm{N}_{2}$. The reactor was sparged continuously at a total rate of $0.1 \mathrm{~L} \mathrm{~min}^{-1}(0.07$ vvm). ${ }^{40}$ Gas concentrations were selected to simulate those from coal combustion emissions from the University of Iowa power plant (Table 2).

Table 2. University of Iowa Power Plant Boiler 10 Coal Combustion Emissions Composition

\begin{tabular}{cc} 
component & mole percent (\%) \\
$\mathrm{H}_{2} \mathrm{O}$ & 12.6 \\
$\mathrm{CO}_{2}$ & 11.6 \\
$\mathrm{O}_{2}$ & 5.8 \\
$\mathrm{CO}$ & 0.048 \\
$\mathrm{SO}_{2}$ & 0.045 \\
$\mathrm{NO}_{2}$ & 0.022 \\
$\mathrm{~N}_{2}$ & 69.9 \\
\hline
\end{tabular}

Because of the toxic nature of the combustion emission gases, experiments were conducted in a walk-in fume hood that housed the entire experimental setup. ${ }^{41}$ The experiments were continually monitored with MultiRAE toxic-gas sensors (RAE Systems, Inc., San Jose, CA, USA).

For each batch experiment, the bioreactor was inoculated to an optical density at $750 \mathrm{~nm}\left(\mathrm{OD}_{750}\right)$ of $0.015 \pm 0.005$ and sampled daily as each batch progressed from lag to stationary phase. Biomass values were calculated from a calibration curve relating $\mathrm{OD}_{750}$ measurements to cell dry weight concentrations (see Figure S2 in the Supporting Information).

Microalgal concentrations were fit with a logistic regression (eq 3) in GraphPad Prism Version 8.1.2

$$
f(x)=\frac{L}{1+\mathrm{e}^{-k\left(x-x_{0}\right)}}
$$

where $L$ is the curve's maximum value $\left(\mathrm{mg} \mathrm{L}^{-1}\right), k$ is the relative steepness of the exponential phase $\left(\mathrm{d}^{-1}\right)$, and $x_{\mathrm{o}}$ is the time of the sigmoidal growth curve's midpoint (d). The maximum biomass productivity was calculated from the derivative of eq 3 at the sigmoid midpoint, where $x=x_{\mathrm{o}}$.

Foaming, which may cause inaccurate biomass concentration measurements, was prevented with 1-2 $\mathrm{mL}$ daily additions (never exceeding $6 \mathrm{~mL}$ per trial) of sterile $1 \%$ antifoam SE-15 solution (Sigma-Aldrich, Inc., Saint Louis, MO, USA) beginning on Day 3 of each microalgal batch. ${ }^{42}$

Inoculum Preparation. S. obliquus inoculum was prepared from pure cultures stored on refrigerated $3 \mathrm{~N}-\mathrm{BBM}$ agar plates. Colonies from the stored plates were used to inoculate $100 \mathrm{~mL}$ of sterile $3 \mathrm{~N}-\mathrm{BBM}$ in $500 \mathrm{~mL}$ Erlenmeyer flasks capped with foam plugs. Cultures were grown in the flasks for approximately $6 \mathrm{~d}$ (the approximate midpoint of the exponential growth phase after transfer from the refrigerated stock), at $25{ }^{\circ} \mathrm{C}$ and $16: 8 \mathrm{~h}$ light cycle, before use in bioreactor experiments.

Control Conditions. Control experiments used Praxair high-purity $\mathrm{CO}_{2}$ and ultra-zero air to attain $12 \% \mathrm{CO}_{2}$. The control cultures had the same temperature, $\mathrm{pH}$, gas flow rate, stirring rate, optical density upon inoculation, and HEPES buffer concentration as the experimental cultures. The culture medium (3N-BBM) was identical with the exception that sulfate $\left(34 \mathrm{mg} \mathrm{L}^{-1}\right)$ was included in the medium for the control experiments, whereas simulated flue gas provided sulfate during the experimental batches. The initial ionic strengths of the media were approximately equal. 
Nutrient Quantification in Flue Gas and the Culture Medium. The concentration of $\mathrm{CO}_{2}$ sparged into the reactor was confirmed using GasLab software and a cozIR wide-range 0-20\% $\mathrm{CO}_{2}$ sensor (CM-0123, Gas Sensing Solutions Ltd., Glasgow, UK).

Sulfate concentrations accumulated, from the sparged simulated flue gases, during the $50 \mathrm{~h}$ bioreactor experiment were quantified using SulfaVer 4 Method 8051 (HACH, Loveland, CO, USA) with a HACH DR6000 UV-Vis spectrophotometer (see Figures S3 \& S4 in the Supporting Information).

During the cultured simulated flue gas trials, sulfate, phosphate, and nitrate concentrations were measured in daily samples of the culture medium $(0.2 \mu \mathrm{m}$ filtered $)$ using an ion chromatograph (Thermo Fisher ICS-2100) equipped with a Dionex IonPac AS18 column. Combined Seven Anion Standard II (Dionex, Sunnyvale, CA) was used to calibrate the instrument.

Microalgal Nutritional Analysis. The protein contents of dried S. obliquus samples were quantified via total nitrogen analysis by Dairy One Forage Labs (Ithaca, NY, USA). The fraction of microalgal protein was estimated from total nitrogen measurements, with a genus-specific conversion factor of $5.05 \pm 0.03$ to exclude nonprotein nitrogen. ${ }^{43}$

Dried microalgal samples were submitted to Bio-Synthesis Inc. (Lewisville, Texas, USA) for amino acid profile analysis using high-performance liquid chromatography.

Microalgal Elemental Composition. The mass percentages of carbon, hydrogen, oxygen, nitrogen, phosphorus, and sulfur were determined at the Iowa State Materials Analysis \& Research Laboratory (see Figures S5 through S10 in the Supporting Information). Carbon, oxygen, hydrogen, sulfur, and nitrogen were quantified through elemental analysis. Sulfur and phosphorus were quantified through energy-dispersive $\mathrm{X}$ ray spectroscopy (FEI Quanta-250 SEM/EDS equipped with an Oxford Instruments X-Max 80 detector).

Bulk Settling Experiments. Static column settling tests, modeled after sludge volume index tests in the wastewater field, were conducted with a $1000 \mathrm{~mL}$ graduated cylinder. Microalgal culture, grown with simulated power plant emissions and harvested on Day 6, was well mixed (200$300 \mathrm{rpm}$ ) prior to pouring the culture into the graduated cylinder to a height of $33.3 \mathrm{~cm}$. The bulk height of the biomass was observed for a period of $30 \mathrm{~min}$. The same procedure was applied to a microalgal control culture grown with $12 \% \mathrm{CO}_{2}$ and ultra-zero air.

Bulk settling was modeled with two-phase exponential decay (eq 4)

$$
f(x)=\left(\operatorname{Span}_{1}\right) \mathrm{e}^{-K_{1} x}+\left(\operatorname{Span}_{2}\right) \mathrm{e}^{-K_{2} x}+\text { plateau }
$$

where $\operatorname{Span}_{1}$ is the region dominated by coagulation and rapid settling, $\mathrm{Span}_{2}$ is the region dominated by compaction, $K_{1}$ is the rate of rapid settling, $K_{2}$ is the rate of compaction, and the plateau is the minimum compacted bulk height.

The fractions of biomass in the settled bulk and the suspended remainder were quantified by measuring the volume and $\mathrm{OD}_{750}$ of each portion. The absence of bacterial contamination as a cause of flocculation was confirmed by phase-contrast microscopy at $100 \times$ magnification and using agar streak plates. The lack of cell death (and subsequent release of cell debris) was confirmed through microscopy at $100 \times$ to search for cell debris and those lacking the green pigment. Prior to microscopy and plating, flocculated samples were rapidly mixed to break up the flocs.

\section{ASSOCIATED CONTENT}

\section{Supporting Information}

The Supporting Information is available free of charge at https://pubs.acs.org/doi/10.1021/acsomega.0c03492.

Image of the experimental setup, biomass versus $\mathrm{OD}_{750 \mathrm{~nm}}$ calibration curve, sulfate concentration versus $\mathrm{OD}_{450 \mathrm{~nm}}$ calibration curve, $50 \mathrm{~h}$ sulfate accumulation, and supplementary elemental analysis and SEM-EDS data (PDF)

\section{AUTHOR INFORMATION}

\section{Corresponding Author}

Hannah R. Molitor - Department of Civil and Environmental Engineering, University of Iowa, Iowa City, Iowa 52240, United States; ○orcid.org/0000-0003-4855-5358; Email: hannahmolitor@uiowa.edu

\section{Author}

Jerald L. Schnoor - Department of Civil and Environmental Engineering, University of Iowa, Iowa City, Iowa 52240, United States

Complete contact information is available at:

https://pubs.acs.org/10.1021/acsomega.0c03492

\section{Author Contributions}

H.R.M. performed the experiments in the laboratory. The idea for the research was from both H.R.M. and J.L.S. equally, and the writing of the manuscript was performed by H.R.M. and edited by J.L.S. Both authors have given approval to the final version of the manuscript.

Notes

The authors declare no competing financial interest.

\section{ACKNOWLEDGMENTS}

This material is based upon work supported by the National Science Foundation Graduate Research Fellowship under grant no. 1546595. Any opinion, findings, and conclusions or recommendations expressed in this material are those of the authors and do not necessarily reflect the views of the National Science Foundation. This material is based upon work also supported by the Iowa Space Grant Consortium under NASA award no. NNX16AL88H, a University of Iowa Graduate and Professional Student Government research grant, and the University of Iowa Foundation, Allen S. Henry endowment. Research was conducted in the W. M. Keck Phytotechnologies Laboratory. The authors would like to thank the University of Iowa power plant staff, especially Mark Maxwell, for their expertise and financial support of the project. The authors would also like to acknowledge Deborah Williard, Amina Grant, Emily Greene, and Carissa Ebling for instrumentation and laboratory assistance.

\section{REFERENCES}

(1) Robinson, T. P.; Pozzi, F. Mapping supply and demand for animal-source foods to 2030. Animal Production and Health Working Paper: Rome, 2011; p 3.

(2) Searchinger, T.; Waite, R.; Hanson, C.; Ranganathan, J. Creating a Sustainable Food Future: A Menu of Solutions to Feed Nearly 10 Billion People by 2050; World Resources Institute, 2018; pp 6-9. 
(3) Matassa, S.; Batstone, D. J.; Hülsen, T.; Schnoor, J.; Verstraete, W. Can Direct Conversion of Used Nitrogen to New Feed and Protein Help Feed the World? Environ. Sci. Technol. 2015, 49, 52475254.

(4) Austic, R. E.; Mustafa, A.; Jung, B.; Gatrell, S.; Lei, X. G. Potential and Limitation of a New Defatted Diatom Microalgal Biomass in Replacing Soybean Meal and Corn in Diets for Broiler Chickens. J. Agric. Food Chem. 2013, 61, 7341-7348.

(5) Vuppaladadiyam, A. K.; Prinsen, P.; Raheem, A.; Luque, R.; Zhao, M. Sustainability Analysis of Microalgae Production Systems: A Review on Resource with Unexploited High-Value Reserves. Environ. Sci. Technol. 2018, 52, 14031.

(6) Cuellar-Bermudez, S. P.; Garcia-Perez, J. S.; Rittmann, B. E.; Parra-Saldivar, R. Photosynthetic bioenergy utilizing CO2: an approach on flue gases utilization for third generation biofuels. $J$. Clean. Prod. 2015, 98, 53-65.

(7) Ho, S.-H.; Chen, C.-Y.; Lee, D.-J.; Chang, J.-S. Perspectives on microalgal CO2-emission mitigation systems - A review. Biotechnol. Adv. 2011, 29, 189-198.

(8) Kumar, P. K.; Vijaya Krishna, S.; Verma, K.; Pooja, K.; Bhagawan, D.; Himabindu, V. Phycoremediation of sewage wastewater and industrial flue gases for biomass generation from microalgae. S. Afr. J. Chem. Eng. 2018, 25, 133-146.

(9) Van Den Hende, S.; Vervaeren, H.; Desmet, S.; Boon, N. Bioflocculation of microalgae and bacteria combined with flue gas to improve sewage treatment. N. Biotech. 2011, 29, 23-31.

(10) Dahl, C.; Hell, R.; Leustek, T.; Knaff, D. Introduction to Sulfur Metabolism in Phototrophic Organisms. In Sulfur Metabolism in Phototrophic Organisms; Hell, R., Dahl, C., Knaff, D., Leustek, T., Eds.; Springer Netherlands: Dordrecht, 2008; pp 1-14.

(11) Giordano, M.; Norici, A.; Ratti, S.; Raven, J. A. Role of Sulfur for Algae: Acquisition, Metabolism, Ecology and Evolution. In Sulfur Metabolism in Phototrophic Organisms; Hell, R., Dahl, C., Knaff, D., Leustek, T., Eds.; Springer Netherlands: Dordrecht, 2008; pp 397415.

(12) Shibagaki, N.; Grossman, A. The State of Sulfur Metabolism in Algae: From Ecology to Genomics. In Sulfur Metabolism in Phototrophic Organisms; Hell, R., Dahl, C., Knaff, D., Leustek, T., Eds.; Springer Netherlands: Dordrecht, 2008; pp 231-267.

(13) Ho, T.-Y.; Quigg, A.; Finkel, Z. V.; Milligan, A. J.; Wyman, K.; Falkowski, P. G.; Morel, F. M. M. The Elemental Composition of Some Marine Phytoplankton1. J. Phycol. 2003, 39, 1145-1159.

(14) Davies, J. P.; Yildiz, F.; Grossman, A. R. Mutants of Chlamydomonas with Aberrant Responses to Sulfur Deprivation. Plant Cell 1994, 6, 53-63.

(15) Mera, R.; Torres, E.; Abalde, J. Effects of sodium sulfate on the freshwater microalgaChlamydomonas moewusii: implications for the optimization of algal culture media. J. Phycol. 2016, 52, 75-88.

(16) Lee, J.-N.; Lee, J.-S.; Shin, C.-S.; Park, S.-C.; Kim, S.-W. Methods to enhance tolerances of Chlorella KR-1 to toxic compounds in flue gas. Appl. Biochem. Biotechnol. 2000, 84 86, 329.

(17) Tabe, L.; Higgins, T. J. V. Engineering plant protein composition for improved nutrition. Trends Plant Sci. 1998, 3, $282-286$.

(18) Hard, D. L. Innovative developments in the production and delivery of alternative protein sources, Expert Consultation and Workshop on Protein Sources for the Animal Feed Industry, Bangkok, Thailand; Food and Agriculture Organization of the United Nations: Bangkok, Thailand, 2002; pp 125-139.

(19) Becker, E. W. Micro-algae as a source of protein. Biotechnol. Adv. 2007, 25, 207-210.

(20) Hesse, H.; Hoefgen, R. Molecular aspects of methionine biosynthesis. Trends Plant Sci. 2003, 8, 259-262.

(21) Schwab, C. G. Amino acids and their appications in formulateing diets for cattle. Mid-South Ruminant Nutrition Conference, 1996; pp 19-32.

(22) Schwab, C. G.; Broderick, G. A. A 100-Year Review: Protein and amino acid nutrition in dairy cows. J. Dairy Sci. 2017, 100, 10094-10112.
(23) Gerardo, M. L.; Oatley-Radcliffe, D. L.; Lovitt, R. W. Minimizing the Energy Requirement of Dewatering Scenedesmus sp. by Microfiltration: Performance, Costs, and Feasibility. Environ. Sci. Technol. 2014, 48, 845-853.

(24) Uduman, N.; Qi, Y.; Danquah, M. K.; Forde, G. M.; Hoadley, A. Dewatering of microalgal cultures: A major bottleneck to algaebased fuels. J. Renew. Sustain. Energy 2010, 2, 012701.

(25) Fasaei, F.; Bitter, J. H.; Slegers, P. M.; van Boxtel, A. J. B. Techno-economic evaluation of microalgae harvesting and dewatering systems. Algal Res. 2018, 31, 347-362.

(26) Xiao, R.; Zheng, Y. Overview of microalgal extracellular polymeric substances (EPS) and their applications. Biotechnol. Adv. 2016, 34, 1225-1244.

(27) Mishra, A.; Jha, B. Isolation and characterization of extracellular polymeric substances from micro-algae Dunaliella salina under salt stress. Bioresour. Technol. 2009, 100, 3382-3386.

(28) Ma, S.; Li, D.; Yu, Y.; Li, D.; Yadav, R. S.; Feng, Y. Application of a microalga, Scenedesmus obliquus PF3, for the biological removal of nitric oxide (NO) and carbon dioxide. Environ. Pollut. 2019, 252, 344-351.

(29) Molitor, H. R.; Moore, E. J.; Schnoor, J. L. Maximum CO2 Utilization by Nutritious Microalgae. ACS Sustainable Chem. Eng. 2019, 7, 9474-9479.

(30) Loladze, I.; Kuang, Y.; Elser, J. J. Stoichiometry in ProducerGrazer Systems: Linking Energy Flow with Element Cycling. Bull. Math. Biol. 2000, 62, 1137-1162.

(31) Madeira, M. S.; Cardoso, C.; Lopes, P. A.; Coelho, D.; Afonso, C.; Bandarra, N. M.; Prates, J. A. M. Microalgae as feed ingredients for livestock production and meat quality: A review. Livest. Sci. 2017, 205, 111-121.

(32) Bleakley, S.; Hayes, M. Algal Proteins: Extraction, Application, and Challenges Concerning Production. Foods 2017, 6, 33.

(33) González-Fernández, C.; Ballesteros, M. Microalgae autoflocculation: an alternative to high-energy consuming harvesting methods. J. Appl. Phycol. 2013, 25, 991-999.

(34) Shipin, O. V.; Meiring, P. G. J.; Phaswana, R.; Kluever, H. Integrating ponds and activated sludge process in the PETRO concept. Water Res. 1999, 33, 1767-1774.

(35) El-Sheekh, M. M.; Khairy, H. M.; El-Shenody, R. Algal production of extra and intra-cellular polysaccharides as an adaptive response to the toxin crude extract of Microcystis aeruginosa. Iran. J. Environ. Health Sci. Eng. 2012, 9, 10.

(36) Angelaalincy, M.; Senthilkumar, N.; Karpagam, R.; Kumar, G. G.; Ashokkumar, B.; Varalakshmi, P. Enhanced Extracellular Polysaccharide Production and Self-Sustainable Electricity Generation for PAMFCs byScenedesmussp. SB1. ACS Omega 2017, 2, 37543765.

(37) Flemming, H.-C.; Wingender, J. The biofilm matrix. Nat. Rev. Microbiol. 2010, 8, 623-633.

(38) Bradley, I. M.; Pinto, A. J.; Guest, J. S. Design and Evaluation of Illumina MiSeq-Compatible, 18S rRNA Gene-Specific Primers for Improved Characterization of Mixed Phototrophic Communities. Appl. Environ. Microbiol. 2016, 82, 5878-5891.

(39) Bischoff, H. W.; Bold, H. C. Some Soil Algae from Enchanted Rock and Related Algal Species; University of Texas: Austin, Tex., 1963; p 1-95.

(40) Huang, Q.; Jiang, F.; Wang, L.; Yang, C. Design of Photobioreactors for Mass Cultivation of Photosynthetic Organisms. Engineering 2017, 3, 318-329.

(41) Molitor, H. R.; Williard, D. E.; Schnoor, J. L. Microalgae Cultivation and Biomass Quantification in a Bench-Scale Photobioreactor with Corrosive Flue Gases. J. Visualized Exp. 2019, 154, No. e60566.

(42) Breuer, G.; de Jaeger, L.; Artus, V. P. G.; Martens, D. E.; Springer, J.; Draaisma, R. B.; Eggink, G.; Wijffels, R. H.; Lamers, P. P. Superior triacylglycerol (TAG) accumulation in starchless mutants of Scenedesmus obliquus: (II) evaluation of TAG yield and productivity in controlled photobioreactors. Biotechnol. Biofuels 2014, 7, 70. 
(43) Templeton, D. W.; Laurens, L. M. L. Nitrogen-to-protein conversion factors revisited for applications of microalgal biomass conversion to food, feed and fuel. Algal Res. 2015, 11, 359-367. 